Теплякова Марина Юрьевна

канд. экон. наук, ФГБОУ ВО «Государственный университет управления», г. Москва,

Российская Федерация

ORCID: 0000-0002-8473-2756

e-mail: teplyakova-marina@yandex.ru

Хабиб Марина Далхатовна канд. экон. наук, ФГБОУ ВО «Государственный университет управления», г. Москва, Российская Федерация

ORCID: 0000-0001-8876-0300

e-mail: marina-khabib@mail.ru

\section{Teplyakova Marina}

Candidate of Economic Sciences, State University of Management, Moscow, Russia

ORCID: 0000-0002-8473-2756

e-mail: teplyakova-marina@yandex.ru

\section{Khabib Marina}

Candidate of Economic Sciences, State University of Management, Moscow, Russia

ORCID: 0000-0001-8876-0300

e-mail: marina-khabib@mail.ru

\section{ИССЛЕДОВАНИЕ РАЗВИТИЯ ЦИФРОВОЙ ЭКОНОМИКИ: РЕГИОНАЛЬНЫЙ АСПЕКТ}

\begin{abstract}
Аннотация. Развитие общества на современном этапе характеризуется практическим внедрением иүирровых технологий во многие сферы жизни. Целью представленного исследования является анализ информачионного обеспечения развития ијировой экономики в регионах Российской Федерации. В статье раскрыты методологические подходы международных и национальных организаций в системе оценки развития информатизации страны. Приведена система показателей национальной системы мониторинга развития ицирровой экономики, отражающая факторы развития информачионного общества и использование информачионных и коммуникационных технологий. Дана сравнительная оценка состава и содержания международных и национальных индикаторов оценки развития информационного общества. Выполнен расчет по составляющим индекса развития информачионных и коммуникационных технологий по каждому субъекту Российской Федерации и по федеральным округам, а также проведен анализ вариации указанного индекса развития по субъектам Российской Федераџии за 2014-2018 г2.
\end{abstract}

Ключевые слова: интегральные индексы, информационно-коммуникационные технологии, мониторинг развития информационного общества, региональное неравенство, рейтинг, система показателей, субъекты Российской Федерации, уровень информатизации, ичифровая экономика.

Цитирование: Теплякова М.Ю., Хабиб М.Д. Исследование развития цифровой экономики: региональный аспект//Вестник университета. 2020. № 4. С. 137-143.

\section{STUDY OF THE DIGITAL ECONOMY DEVELOPMENT: REGIONAL ASPECT}

\begin{abstract}
The development of society at the present stage is characterized by the practical implementation of digital technologies in many areas of life. The purpose of this study is to analyze the information support of the development of the digital economy in the regions of the Russian Federation. The methodological approaches of international and national organizations in the system for assessing the development of the country's informatization have been disclosed in the article. A system of indicators of the national system for monitoring the development of the digital economy, which reflects the development factors of the information society and the use of information and communication technologies, has been presented. A comparative assessment of the composition and content of international and national indicators for assessing the development of the information society has been given. The calculation on the components of the information and communication technologies Development Index for each subject of the Russian Federation and the Federal districts has been made, as well as the analysis of variations in this Development Index for the constituent entities of the Russian Federation for 2014-2018 has been carried out.
\end{abstract}

Keywords: digital economy, constituent entities of the Russian Federation, monitoring the development of the information society, scorecard, rating, integrated indices, information and communication technologies, level of informatisation, regional inequality.

For citation: Teplyakova M.Yu., Khabib M.D. (2020) Study of the digital economy development: regional aspect. Vestnik universiteta. I. 4, pp. 137-143. DOI: 10.26425/1816-4277-2020-4-137-143

Успешная реализация государственных программ Российской Федерации (далее - РФ) по развитию цифровой экономики как на федеральном, так и на региональном уровнях возможна только при наличии выстроенной инфраструктуры их обеспечения и адекватной системы управления. Изучение хода реализации таких программ предполагает формирование системы информационного обеспечения, направленной на получение и обработку достаточного объема качественной, актуальной и большого объема достоверной информации, необходимой для анализа происходящих процессов в данной сфере [2; 8].

(C) Теплякова М.Ю., Хабиб М.Д., 2020. Статья доступна по лицензии Creative Commons «Attribution» («Атрибуция») 4.0. всемирная (http://creativecommons.org/licenses/by/4.0/).

The Author(s), 2020. This is an open access article under the CC BY 4.0 license (http://creativecommons.org/licenses/by/4.0/).

(c) (i) 
В настоящее время (с 2016 г.) Министерство цифрового развития, связи и массовых коммуникаций РФ (далее - Минкомсвязь России) совместно с Федеральной службой государственной статистики (далее Росстат) и другими ведомствами проводит мониторинг российских регионов с целью изучения текущего состояния и динамики развития регионального уровня информатизации $[9 ; 10]$.

Система показателей оценки уровня информатизации основана на «Методике оценки уровня развития информационного общества в субъектах Российской Федерации», которую разработала Минкомсвязь России в 2016 г. [6]. Данная методика позволяет получать информацию не только об уровне развития информационного общества регионов во всех сферах деятельности, но и дает возможность получать обобщающую рейтинговую оценку регионов по уровню информационного развития.

Построение рейтингов в исследованиях является на сегодняшний день достаточно востребованным направлением как за рубежом, так и в РФ [3; 4; 7; 13]. Его основное преимущество - получение моментной оценки изучаемого явления по различным объектам исследования.

Для принятия решения о выборе и включении определенных индикаторов в систему оценок необходимо учитывать простые критерии, доступные для каждой страны или ее региона [2]. При этом, каждый индикатор должен: решать только одну проблему, иметь достаточно надежные данные измерений, основываться на международно согласованных методологиях.

По данным ООН на международном уровне рассчитывается и публикуется с различной периодичностью около 180 различных рейтингов [13]. Возможность ранжирования субъектов РФ по уровню информатизации позволяет выявить лидирующие и отстающие регионы в этой области, оценить степень их информационного неравенства, а правительствам регионов принять необходимые и эффективные управленческие решения по устранению этого неравенства.

Определение рейтинга информационного развития отдельных субъектов РФ выполняется по Интегральному индексу развития информационного общества. За его основу был взят международный опыт построения сводных индексов в области информационного развития [7]. Были приняты во внимание методологии построения следующих международных индексов:

- индекс развития информационно-коммуникационных технологий (далее - ИКТ) (ICT Development Index, IDI),

- индекс развития электронного правительства (E-Government Development Index, EGDI).

- индекс готовности к сетевому обществу (Networked Readiness Index, NRI).

Индекс развития ИКТ и индекс развития электронного правительства являются разработкой ООН, а индекс готовности к сетевому обществу разработан Всемирным экономическим форумом. Индекс развития ИКТ представляют собой обобщающую оценку развития ИКТ в отдельных странах (рассчитывается ежегодно с 2007 г.). Индекс готовности к сетевому обществу отражает готовность отдельных стран к использованию возможностей ИКТ (рассчитывается ежегодно с 2002 г.). Индекс развития электронного правительства - обобщающий индикатор степени готовности национальных государственных структур к использованию ИКТ при оказании государственных услуг населению (рассчитывается с 2003 г. один раз в два года).

Интегральный индекс развития информационного общества в субъектах РФ имеет двухуровневую структуру (табл. 1). В его состав входят два индекс-компонента: «факторы развития информационного общества» и «использование ИКТ для развития» [9; 10]. Каждый из индекс-компонентов включает в себя ряд подындексов. Первый индекс-компонент состоит из четырех подындексов, а второй из пятнадцати подындексов.

Таблииа 1

\section{Структура интегрального индекса развития информационного общества в субъектах Российской Федерации}

\begin{tabular}{|l|l|}
\hline \multicolumn{1}{|c|}{ Индекс-компоненты } & \multicolumn{1}{|c|}{ Подындексы } \\
\hline \multirow{2}{*}{ Факторы развития информационного } & Человеческий капитал \\
общества & ИКТ - инфраструктура \\
$(1 / 3)$ & Экономическая среда \\
\hline
\end{tabular}




\begin{tabular}{|l|l|}
\hline \multicolumn{1}{|c|}{ Индекс-компоненты } & \multicolumn{1}{c|}{ Подындексы } \\
\hline \multirow{5}{*}{$\begin{array}{l}\text { Использование ИКТ } \\
\text { для развития (2/3) }\end{array}$} & $\begin{array}{l}\text { Электронное правительство } \\
\text { Использование ИКТ в домохозяйствах и населением } \\
\text { Использование ИКТ в сфере предпринимательства и торговли } \\
\text { Использование ИКТ в сфере здравоохранения } \\
\text { Использование ИКТ в сфере образования } \\
\text { Использование ИКТ в сфере транспорта } \\
\text { Использование ИКТ в сфере строительства } \\
\text { Использование ИКТ в сфере обеспечения жизнедеятельности } \\
\text { Использование ИКТ в сфере сельского хозяйства } \\
\text { Использование ИКТ в сфере жилищно-коммунального хозяйства } \\
\text { Использование ИКТ в сфере государственных и муниципальных финансов } \\
\text { Использование ИКТ в сфере социальной защиты населения } \\
\text { Использование ИКТ в сфере труда и занятости } \\
\text { Использование ИКТ в сфере энергетики }\end{array}$ \\
\hline
\end{tabular}

Источник: [6]

Следует отметить, что вес индекс-компонента «Факторы развития информационного общества» составляет $1 / 3$ в значении Интегрального индекса развития информационного общества, а на индекс-компонент «Использование ИКТ для развития» приходится $2 / 3$ веса в значении индекса. Веса подындексов в значении индекс-компонентов распределяются пропорционально числу их составляющих.

При расчете Интегрального индекса развития информационного общества в субъектах РФ используются нормированные значения показателей. Нормированное значение показателя определяется в соответствии с методикой нормализации значений, применяемой при расчете индекса развития ИКТ (IDI), то есть отношением фактического значения к его эталонному значению.

Первый рейтинг субъектов РФ по уровню развития информационного общества был составлен в конце 2016 г. Его результаты позволили установить пять лидирующих субъектов в области информатизации. Это города-столицы: Москва и Санкт-Петербург, два региона тесно связанных с добычей нефти и газа: ХантыМансийский автономный округ - Югра и Ямало-Ненецкий автономный округ и Калининградская область регион, который в последние годы зарекомендовал себя как один из самых динамично развивающихся.

Расчет интегрального индекса развития информационного общества связан с достаточно большим объемом показателей (более 100), а также с целью повышения степени достоверности и актуальности первичной информации, Минкомсвязью России была разработана автоматизированная информационная система «Электронный регион».

Благодаря внедрению этой системы была полностью автоматизирована процедура сбора и обработки данных для расчета индекса развития информационного общества субъектов РФ и построения по его значениям регионального мониторинга уровня информатизации.

Однако, доступ в данную систему предназначен только для органов федеральной и региональной исполнительной власти. В открытом доступе находится четыре позиции:

- топ-5 регионов по объемам ИКТ-бюджетов (за два последних отчетных года);

- структура ИКТ-расходов регионов в разрезе трех основных направлений внедрения ИКТ;

- отраслевая структура расходов регионов ИТ-бюджетов (за три последних отчетных года);

- топ-5 регионов по росту расходов на ИКТ (за два последних отчетных года).

С целью изучения уровня информатизации регионов РФ, авторы выполнили расчет и проанализировали в динамике индекс развития ИКТ по субъектам РФ за 2014-2018 гг. 
Данный индекс был рассчитан с использованием международной методологии расчета индекса развития ИКТ 2007 г.

По данной методике индекс развития ИКТ представляет собой систему трех подындексов:

- подындекс доступа к ИКТ;

- подындекс использования ИКТ;

- подындекс навыков использования ИКТ.

Причем, вес первого и второго подындексов составляет 40 \%, а на третий подындекс приходится $20 \%$ веса индекса развития ИКТ.

В составе подындекса доступа к ИКТ пять показателей:

- число абонентов фиксированной телефонной сети на 100 человек населения;

- число абонентов мобильной сотовой связи на 100 человек населения;

- пропускная способность международных каналов Интернета на одного пользователя;

- удельный вес домашних хозяйств, имеющих персональный компьютер, в общем числе домашних хозяйств;

- удельный вес домашних хозяйств, имеющих доступ к Интернету, в общем числе домашних хозяйств.

В подындексе использования ИКТ - три показателя:

- удельный вес населения - пользователей Интернета в общей численности населения;

- число абонентов фиксированного широкополосного доступа в Интернет на 100 человек населения;

- число абонентов мобильного широкополосного доступа в Интернет на 100 человек населения.

В подындексе практических навыков использования ИКТ - три показателя.

- средняя продолжительность обучения;

- валовой охват средним образованием;

- валовой охват высшим образованием.

Распределение весов показателей в подындексах происходит пропорционально их количеству [6].

В официальных статистических публикациях по регионам РФ из 11 индикаторов входящих в состав индекса развития ИКТ по методике 2007 г. отсутствует три, которые входят в состав Подындекса практических навыков использования ИКТ. Они были заменены достаточно близкими по содержанию показателями: уровень грамотности населения, удельный вес студентов, обучающихся по программе подготовки специалистов среднего звена в общей численности населения и удельный вес студентов, обучающихся по образовательным программам высшего образования в общей численности населения. Данные показатели используют в расчете подындекса Человеческий капитал в интегральном индексе развития информационного общества [5].

Расчет индекса развития ИКТ был выполнен по каждому субъекту РФ и по Федеральным округам по данным мониторинга развития информационного общества в РФ [2; 5]. Произведенные расчеты позволили составить и проанализировать рейтинг федеральных округов по значениям подындексов-составляющих индекса развития ИКТ (табл. 2).

Таблица 2

Рейтинги федеральных округов Российской Федерации по составляющим индекса развития информационно-коммуникационных технологий

\begin{tabular}{|l|c|c|c|c|c|c|c|c|c|c|c|c|c|c|c|}
\hline \multirow{2}{*}{\multicolumn{1}{|c}{ Федеральный округ }} & \multicolumn{2}{|c|}{2014 г. } & \multicolumn{3}{c|}{2015 г. } & \multicolumn{3}{c|}{2016 г. } & \multicolumn{3}{c|}{2017 г. } & \multicolumn{3}{c|}{2018 г. } \\
\cline { 2 - 14 } & SI1 & SI2 & SI 3 & SI1 & SI2 & SI3 & SI1 & SI2 & SI3 & SI1 & SI2 & SI3 & SI1 & SI2 & SI3 \\
\hline Центральный & 2 & 1 & 1 & 2 & 1 & 1 & 2 & 5 & 1 & 1 & 1 & 1 & 1 & 1 & 1 \\
Северо-Западный & 1 & 5 & 2 & 1 & 4 & 3 & 1 & 3 & 2 & 2 & 3 & 3,5 & 2 & 4 & 3 \\
Южный & 7 & 2 & 7 & 5 & 3 & 7 & 5 & 2 & 7 & 5 & 7 & 7 & 5 & 7 & 7 \\
Северо-Кавказский & 8 & 3 & 8 & 7 & 8 & 8 & 6 & 7 & 8 & 3 & 8 & 8 & 8 & 8 & 8 \\
Приволжский & 4 & 7 & 5 & 4 & 6 & 4 & 4 & 6 & 3 & 6 & 4 & 2 & 4 & 5 & 4 \\
Уральский & 3 & 6 & 3,5 & 3 & 7 & 5 & 3 & 8 & 5 & 4 & 5 & 5 & 3 & 3 & 5 \\
Сибирский & 5 & 8 & 3,5 & 8 & 5 & 2 & 7 & 4 & 4 & 8 & 6 & 3,5 & 6 & 6 & 2 \\
Дальневосточный & 6 & 4 & 6 & 6 & 2 & 6 & 8 & 1 & 6 & 7 & 2 & 6 & 7 & 2 & 6 \\
\hline
\end{tabular}

Источники: [5; 9] 
Анализ рейтинга федеральных округов по значениям составляющих индекса развития ИКТ показал, что лидером в сфере развития информатизации на протяжении всего рассматриваемого периода был Центральный федеральный округ, а отстающим - Северо-Кавказский федеральный округ. Остальные федеральные округа в рассматриваемый период имели достаточно неустойчивые позиции по значениям составляющих указанного индекса, что не позволило установить их место в рейтинге.

В таблице 3 представлены значения индекса развития ИКТ по федеральным округам РФ и их место в рейтинге по значению за 2014-2018 гг. Устойчиво первые три места по индексу развития ИКТ в данном периоде занимали Центральный, Северо-западный и Южный федеральные округа соответственно. Улучшили свои позиции в рейтинге к 2018 г. Приволжский федеральный округ (с шестого на четвертое место) и Сибирский федеральный округ (с седьмого на шестое место). У округов Южный и Сибирский к 2018 г. рейтинги понизились. Последнее место в рейтинге в течение всего периода принадлежало Северо-Кавказскому федеральному округу.

Таблица 3

\section{Индекс развития информационно-коммуникационных технологий федеральных округов Российской Федерации в 2014-2018 гг.}

\begin{tabular}{|l|c|c|c|c|c|c|}
\hline \multirow{2}{*}{ Федеральный округ } & \multicolumn{3}{|c|}{$\mathbf{2 0 1 4}$ г. } & \multicolumn{3}{c|}{2018 г. } \\
\cline { 2 - 7 } & $\begin{array}{c}\text { значение } \\
\text { показателя }\end{array}$ & $\begin{array}{c}\text { место } \\
\text { в рейтинге }\end{array}$ & $\begin{array}{c}\text { коэффициент } \\
\text { вариации, \% }\end{array}$ & $\begin{array}{c}\text { значение } \\
\text { показателя }\end{array}$ & $\begin{array}{c}\text { место } \\
\text { в рейтинге }\end{array}$ & $\begin{array}{c}\text { коэффициент } \\
\text { вариации, \% }\end{array}$ \\
\hline Центральный & 5,73 & 1 & 14,2 & 6,28 & 1 & 11,4 \\
Северо-Западный & 5,69 & 2 & 6,7 & 6,05 & 2 & 6,1 \\
Южный & 5,32 & 5 & 31,2 & 5,57 & 7 & 12,8 \\
Северо-Кавказский & 4,62 & 8 & 13,9 & 5,13 & 8 & 8,5 \\
Приволжский & 5,26 & 6 & 3,3 & 5,78 & 4 & 5,7 \\
Уральский & 5,41 & 3 & 11,2 & 5,86 & 3 & 11,2 \\
Сибирский & 5,17 & 7 & 3,8 & 5,65 & 6 & 5,3 \\
Дальневосточный & 5,40 & 4 & 11,3 & 5,77 & 5 & 10,7 \\
\hline
\end{tabular}

Истчоники: [5; 9]

В рамках исследования авторами был проведен также анализ вариации Индекса развития ИКТ по субъектам РФ. Выполненный анализ показал, что во всех федеральных округах РФ вариация исследуемого индекса в субъектах в период 2014-2018 гг. была достаточно однородна, о чем свидетельствуют значения коэффициента вариации (см. табл. 3). Практически по всем федеральным округам наблюдается тенденция снижения этого показателя. Если в 2014 г. он варьировался от 6,7 \% до 31,2 \%, то к 2018 г. значения коэффициента вариации находились уже в пределах от 5,3 \% до 12,8 \%. Данную тенденцию можно объяснить ходом реализации в регионах государственной программы «Цифровая экономика Российской Федерации» которая начала действовать во второй половине 2017 г. [1]. То есть можно сказать, что решение задач по цифровизации экономики на государственном уровне позволяет снизить в определенной степени неравенство регионов РФ в развитии по данному направлению.

Эволюция и развитие информационных технологий в мире привели к тому, что на внеочередном совещании (март 2017 г.) международной группы экспертов Международного союза электросвязи (далее - МСЭ) были предложены изменения в составе индикаторов индекса развития ИКТ (IDI), которые вступили в силу в 2019 г. [11].

Было принято включить в состав индекса развития ИКТ 14 показателей, а не 11 как было ранее. Из текущего списка индикаторов индекса развития ИКТ были исключены два показателя: число абонентов фиксированной телефонной сети на 100 человек населения и число абонентов мобильной сотовой связи на 100 человек населения. В то же время были добавлены пять новых показателей: удельный вес населения, охваченного мобильными сетями не менее $3 \mathrm{G}$ и как минимум LTE/WiMAX, мобильный широкополосный интернет-трафик по мобильной широкополосной подписке, фиксированный широкополосный интернет-трафик 
по фиксированной широкополосной подписке, удельный вес населения, у которых есть мобильный телефон и удельный вес населения с навыками ИКТ [12].

В ходе проведенного исследования было установлено, что несмотря на единую концепцию в методологии изучения внедрения и развития информационно-коммуникационных технологий, наблюдаются некоторые различия в составе и содержании показателей, применяемых на международном и национальном уровнях. Кроме того, на национальном уровне требуется согласованность содержания показателей, представляемых различными ведомствами. Анализ индекса развития информационно-коммуникационных технологий по регионам Российской Федерации показал положительную его динамику с 2014 г. по 2018 г., а также сглаживание относительного неравенства в развитии информатизации субъектов Российской Федерации.

\section{Библиографический список}

1. Программа «Цифровая экономика РФ», утвержденная распоряжением Правительства РФ от 28.07.2017 г. № 1632-Р // СПС «КонсультантПлюс» [Электронный ресурс]. - Режим доступа: http://consultant.ru/document/cons_doc_LAW_221756/ (дата обращения: 10.01.2020).

2. Егоренко, С. Н. Официальная статистика в условиях формирования цифровой экономики в Российской Федерации // Вопросы статистики. - 2018. - № 25 (10). - С. 3-6.

3. Ефимова, М. Р., Долгих, Е. А. Статистический анализ развития информационного общества в Российской Федерации // Вестник Университета. - 2018. - № 9. - С. 90-94.

4. Ефимова, М. Р., Долгих, Е. А., Паршинцева, Л. С. Статистические исследования становления цифровой экономики в Российской Федерации: Монография. - М.: Издательский дом ГУУ, 2018. - 122 с.

5. Информационное общество: основные характеристики субъектов Российской Федерации: статистический сборник / М. А. Сабельникова, Г. И. Абдрахманова, Л. М. Гохберг, О. Ю. Дудорова и др.; Росстат; Нац. исслед. ун-т «Высшая школа экономики». - М.: НИУ ВШЭ, 2018. - 216 с.

6. Методика оценки уровня развития информационного общества в субъектах Российской Федерации / Министерство цифрового развития, связи и массовых коммуникаций Российской Федерации 2016 [Электронный ресурс]. - Режим доступа: https://digital.gov.ru/ru/documents/4949/ (дата обращения: 30.01.2020)

7. Национальный индекс развития цифровой экономики: пилотная реализация. М.: ГК «Росатом», 2018. - 92 с. [Электронный ресурс]. - Режим доступа: https://www.researchgate.net/publication/331470670_Nacionalnyj_indeks_razvitia_cifrovoj_ ekonomiki_Pilotnaa_realizacia (дата обращения: 14.02.2020).

8. Хабиб, М. Д., Теплякова, М. Ю. О формировании институциональной среды цифровой экономики // Шаг в будущее: искусственный интеллект и цифровая экономика. Материалы II Международного научного форума. Вып. 5 / Государственный университет управления. - М.: Издательский дом ГУУ, 2018. - С. 295-300.

9. Министерство цифрового развития, связи и массовых коммуникаций Российской Федерации [Электронный ресурс]. Режим доступа: http:///www.minsvyaz.ru (дата обращения: 14.02.2020).

10. Федеральная служба государственной статистики [Электронный ресурс]. - Режим доступа: http://www.gks.ru (дата обращения: 10.01.2020).

11. Big data for measuring the information society methodology // International Telecommunication Union. Geneva, 2017.

12. International Telecommunication Union [Электронный ресурc]. - Режим доступа: http://www.itu.int (дата обращения: 04.02.2020).

13. Report of the Partnership on Measuring Information and Communication Technology for Development // Statistical Commission. Fifty-first session. 3-6 March 2020. Economic and Social Council United Nations [Электронный ресурс]. - Режим доступа: https://unstats.un.org/unsd/statcom/51st-session/documents/2020-23-ICT-EE.pdf (дата обращения: 04.04.2020).

\section{References}

1. Programma “Tsifrovaya ekonomika RF”, utverzhdennaya rasporyazheniyem Pravitel'stva RF ot 28.07.2017 g. No. 1632-R [Program "Digital Economy of the Russian Federation", approved by Order of the Government of the Russian Federation No. 1632-R, dated on July 28, 2017]. Legal reference system "Consultant Plus". Available at: http://consultant.ru/document/ cons_doc_LAW_221756/(accessed 10.01.2020).

2. Egorenko S. N. Ofitsial'naya statistika na fone poyavleniya tsifrovoi ekonomiki v Rossiiskoi Federatsii [Official statistics amidst the emergence of the digital economy in the Russian Federation]. Voprosy statistiki [Statistics questions], 2018, no. 25 (10), pp. 3-6. 
3. Efimova M. R., Dolgikh E. A., Statisticheskii analiz razvitiya informatsionnogo obshchestva v Rossiiskoi Federatsii [Statistical analysis of the development of the information society in the Russian Federation].Vestnik Universiteta, 2018, no. 9, pp. 90-94.

4. Efimova M. R., Dolgikh E. A., Pashintseva L. S. Statisticheskie issledovaniya stanovleniya tsifrovoi ekonomiki v Rossiiskoi Federatsii: monografiya [Statistical study of the emergence of the digital economy in the Russian Federation: monograph]. Moscow, Izd. dom GUU, 2018. 122 p.

5. Sabel'nikova M. A., Abdrakhmanova G. I., Gokhberg L. M., Dudorova O. Yu. et al. Informatsionnoe obshchestvo: osnovnye kharakteristiki sub"ektov Rossiiskoi Federatsii: statisticheskii sbornik [Information society: the main characteristics of the constituent entities of the Russian Federation: statistical compilation]. Rosstat; Nats. issled. un-t "Vysshaya shkola ekonomiki" [Rosstat; National Research University "Higher School of Economics]. Moscow, NIU VSHE, 2018. 216 p.

6. Metodika otsenki urovnya razvitiya informatsionnogo obshchestva v sub"yektakh Rossiiskoi Federatsii [Methodology for assessing the level of development of the information society in the constituent entities of the Russian Federation]. Ministerstvo tsifrovogo razvitiya, svyazi i massovykh kommunikatsii Rossiiskoi Federatsii 2016 [Ministry of Digital Development, Communications and Mass Media of the Russian Federation 2016]. Available at: https:/digital.gov.ru/ru/documents/4949/ (accessed 30.01.2020).

7. Natsional'nyi indeks razvitiya tsifrovoi ekonomiki: Pilotnaya realizatsiya [National Digital Economy Development Index: Pilot implementation]. Moscow, GK “Rosatom”, 2018. 92 p. Available at: https://www.researchgate.net/publication/331470670_Nacionalnyj_indeks_razvitia_cifrovoj_ekonomiki_Pilotnaa_realizacia (accessed 14.02.2020).

8. Khabib M. D., Teplyakova M. Y. O formirovanii institutsional'noi sredy tsifrovoi ekonomiki [About formation of the institutional environment of the digital economy]. Shag v budushchee: iskusstvennyi intellekt i tsifrovaya ekonomika. Materialy II Mezhdunarodnogo nauchnogo foruma. Vyp. 5 [Step into the future: artificial intelligence and the digital economy. Proceedings of the II International Scientific Forum. Issue 5]. Gosudarstvennyi Universitet Upravleniya. Moscow, Izd. dom GUU, 2018, pp. 295-300.

9. Ministerstvo tsifrovogo razvitiya, svyazi i massovykh kommunikatsii Rossiiskoi Federatsii [Ministry of Digital Development, Communications and Mass Media of the Russian Federation]. Available at: http:///www.minsvyaz.ru (accessed14.02.2020).

10. Federal'naya sluzhba gosudarstvennoi statistiki [Federal State Statistics Service]. Available at: http://www.gks.ru/ (accessed 10.01.2020).

11. Big data for measuring the information society methodology. International Telecommunication Union. Geneva, 2017.

12. International Telecommunication Union. Available at: http://www.itu.int (accessed 04.02.2020).

13. Report of the Partnership on Measuring Information and Communication Technology for Development. Statistical Commission, Fifty-first session, 3-6 March 2020. Economic and Social Council United Nations. Available at: https:/unstats.un.org/unsd/ statcom/51st-session/documents/2020-23-ICT-EE.pdf (accessed 04.04.2020). 